Oxide dispersion strengthened stainless steel $316 \mathrm{~L}$ with superior strength and ductility by selective laser melting

\title{
Zhong, Yuan
}

2020-04-01

Zhong , Y , Liu , L , Zou , J , Li , X , Cui , D \& Shen , Z 2020 , ' Oxide dispersion strengthened stainless steel $316 \mathrm{~L}$ with superior strength and ductility by selective laser melting ' , Journal of Materials Science \& Technology , vol. 42 , pp. 97-105 . https://doi.org/10.1016/j.jmst.2019.11.00

http://hdl.handle.net/10138/336348

https://doi.org/10.1016/j.jmst.2019.11.004

cc_by_nc_nd

acceptedVersion

Downloaded from Helda, University of Helsinki institutional repository.

This is an electronic reprint of the original article.

This reprint may differ from the original in pagination and typographic detail.

Please cite the original version. 


\section{Journal Pre-proof}

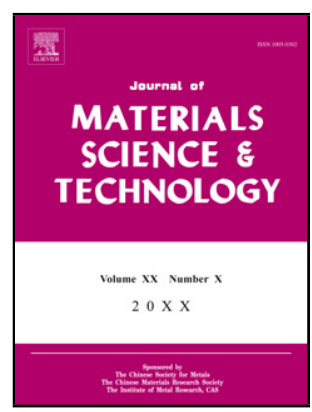

Oxide dispersion strengthened stainless steel $316 \mathrm{~L}$ with superior strength and ductility by selective laser melting

Yuan Zhong, Leifeng Liu, Ji Zou, Xiaodong Li, Daqing Cui, Zhijian Shen

PII:

S1005-0302(19)30441-4

DOI:

https://doi.org/10.1016/j.jmst.2019.11.004

Reference:

JMST 1838

To appear in:

Journal of Materials Science \& Technology

Received Date:

14 August 2019

Revised Date:

30 September 2019

Accepted Date:

7 October 2019

Please cite this article as: Zhong Y, Liu L, Zou J, Li X, Cui D, Shen Z, Oxide dispersion strengthened stainless steel $316 \mathrm{~L}$ with superior strength and ductility by selective laser melting, Journal of Materials Science and Technology (2019), doi: https://doi.org/10.1016/j.jmst.2019.11.004

This is a PDF file of an article that has undergone enhancements after acceptance, such as the addition of a cover page and metadata, and formatting for readability, but it is not yet the definitive version of record. This version will undergo additional copyediting, typesetting and review before it is published in its final form, but we are providing this version to give early visibility of the article. Please note that, during the production process, errors may be discovered which could affect the content, and all legal disclaimers that apply to the journal pertain.

(c) 2019 Published by Elsevier. 


\section{Research Article \\ Oxide dispersion strengthened stainless steel 316L with superior strength and ductility by selective laser melting}

Yuan Zhong ${ }^{1}$, Leifeng Liu $^{2}$, Ji Zou ${ }^{2}$, Xiaodong Li $^{3}$, Daqing Cui ${ }^{1}$, Zhijian Shen ${ }^{1} *$

${ }^{1}$ Department of Materials and Environmental Chemistry, Arrhenius Laboratory, Stockholm University, SE-10691 Stockholm, Sweden

${ }^{2}$ School of Metallurgy and Materials, University of Birmingham, B15 2TT, UK

${ }^{3}$ Department of Chemistry-Radiochemistry, P.O. Box 55, FI-00014 University of Helsinki, Finland

* Corresponding author. Prof. Zhijian Shen, Ph.D.; Tel.: +46 (0)8 1623 88. E-mail address: shen@mmk.su.se (Z.J. Shen).

[Received 14 August 2019; revised 30 September 2019; accepted 7 October 2019]

Dense oxide dispersion strengthened (ODS) 316L steels with different amount of $\mathrm{Y}_{2} \mathrm{O}_{3}$ additions were successfully fabricated by selective laser melting (SLM) even though part of the added $\mathrm{Y}_{2} \mathrm{O}_{3}$ got lost during the process. The microstructure was characterized in details and the mechanical properties were tested at room temperature, $250^{\circ} \mathrm{C}$ and $400^{\circ} \mathrm{C}$, respectively. The effect of the scanning speed on agglomeration of nanoparticles during SLM process was discussed. Superior properties, e.g., yield strength of $574 \mathrm{MPa}$ and elongation of $91 \%$, were achieved at room temperature in SLM ODS 316L with additional $1 \%$ of $\mathrm{Y}_{2} \mathrm{O}_{3}$. At elevated temperatures, the strength kept high but the elongations dropped dramatically. It was observed that nano-voids nucleated throughout the whole gauge section at the sites where nanoinclusions located. The growth and coalescence of these voids were suppressed by the formation of an element segregation network before necking, which relieved local stress concentration and thus delayed necking. This unusual necking behavior was studied and compared to the previous theory. It appeared that the strong convection presented in the melt pool can evenly redistribute the short-time milled coarse $\mathrm{Y}_{2} \mathrm{O}_{3}$ precursor powder during SLM process. These findings can not 
only solve the problems encountered during the fabrication of ODS components but also replenish the strengthening mechanism of SLM 316L thus pave a way for further improving of mechanical properties.

Keywords: ODS steel; selective laser melting (SLM); Elevated-temperature properties; Necking; Strain hardening

\section{Introduction}

Austenite stainless steel is a good candidate structural material suitable for using at temperature up to $600^{\circ}$ due to its good ductility, corrosion resistance, oxidation resistance and comparably low cost. For example, this family of steels is widely used as the structural materials in nuclear reactors. On the other hand, the lower yield strength and creep strength limit its applications at elevated temperature. One solution to overcome these problems is to introduce stable oxide nanoinclusions in the steel matrix to form the so called oxide dispersion strengthening steel (ODS). ${ }^{[1-5]}$ Conventionally, ODS parts are fabricated through a complicated process by involving many steps such as mechanical alloying (MA), degassing, hot extrusion, rolling and heat treatment. ${ }^{[6,7]}$ In addition, ODS parts are known difficult to join, because the added fine oxide nanoinclusions may agglomerate and coarsen during welding. ${ }^{[8]}$ Thus, developing new fabrication and joining techniques for ODS is demanded.

Selective laser melting (SLM) is an additive manufacturing (AM) method that can fabricate 3D components with complex structures in one step layer-by-layer by fusing together melt pools formed under a scanning laser beam. ${ }^{[9-11]}$ Successful results have been obtained to fabricate nanocomposites by laser melting of ball milled powder mixtures. ${ }^{[12,13]}$ The freedoms in manipulating both the geometries and the internal structures of the parts and the feasibility of forming parts made of ODS materials in a single step makes SLM a manufacturing method with great potential for ODS parts. Therefore, many studies have been carried out to explore the potential of different AM methods, including SLM, selective electron beam melting (SEBM) ${ }^{[14]}$ and laser metal deposition (LMD) ${ }^{[15]}$, in the preparation of ODS parts. Walker et al. fabricated PM2000 thin walls by SLM and found the coarsening and agglomeration of oxide nanoinclusions was influenced by laser scanning speed. ${ }^{[16]}$ Hunt et al. tried to build MA956 bulk samples by SLM and observed the formation of micro-sized agglomerates of 
nanoinclusions that deteriorated the mechanical properties. ${ }^{[17]}$ Chang et al. used a laser beam to melt a powder mixture of steel and $\mathrm{Y}_{2} \mathrm{O}_{3}(20-50 \mathrm{~nm})$ on the steel surface and observed the formation of $\mathrm{Y}_{2} \mathrm{Ti}_{2} \mathrm{O}_{7}$ oxide particles that coarsened to $150 \mathrm{~nm}$ due to the active agglomeration of Y-Ti-O nanoinclusions, carbides and Ar bubbles. ${ }^{[18]}$ Vasquez et al achieved $98 \%$ of density and the fine dispersion of nanosized Y-Ti-O particles by using a powder mixture (steel, $\mathrm{Y}_{2} \mathrm{O}_{3}$ and $\mathrm{TiH}_{2}$ ) prepared by ball milling for extended duration of 176 hours. ${ }^{[19]}$ Boegelein et al. fabricated ferritic ODS-PM2000 samples by SLM from a pre-alloyed powder, in which non-randomly occurred voids, up to $150 \mu \mathrm{m}$ in size, and inclusions up to $50 \mu \mathrm{m}$ in size were observed. Smaller pores $(\leq 20 \mu \mathrm{m}$ in size) and finely distributed nanoinclusions with a mean size of $17 \mathrm{~nm}$ formed inside the thin walls. Nevertheless, the mechanical properties of the as-built ODS-PM2000 were still not as good as the conventional extruded ones. ${ }^{[20]}$ Post heat treatment could increase the concentration of small nanoinclusions $(5-15 \mathrm{~nm})$ but the loss of Y and the formation of defects during SLM were reported in another study of the same material performed by the same group. ${ }^{[21]}$ Zhang et al. noticed the active reaction of the additional $\mathrm{Y}$ element and the segregation of Y-rich oxides during SLM process can purify the oxygen in the final material obtained from blended powder (316L stainless steel powder and Fe-based amorphous powder). ${ }^{[22]}$ Gao et al. used SEBM to fabricate ball milled mixture of ferritic powder, $\mathrm{W}(800 \mathrm{~nm}), \mathrm{Ti}(50 \mathrm{~nm})$ and $\mathrm{Y}_{2} \mathrm{O}_{3}(40 \mathrm{~nm})$. A homogeneous dispersion of oxide precipitates was achieved in small sized blocks $(22 \mathrm{~mm} \times 10 \mathrm{~mm} \times 12 \mathrm{~mm})$ and a better strength but lower ductility of annealed samples was obtained at elevated temperatures. ${ }^{[23]}$ The same group also tried EBSM fabricating austenitic 316L steel from ball milled powder mixture of $316 \mathrm{~L}$ steel powder $(50-100 \mu \mathrm{m})$ and $\mathrm{Y}_{2} \mathrm{O}_{3}$ powder $(\leq 40 \mathrm{~nm})$. They obtained EBSM-ODS-316L with tensile strength of $410 \mathrm{MPa}$, total elongation of $51.2 \%$ and hardness of 146 (HV0.2). Springer et al. developed a new way of producing oxide- and nitride- dispersion strengthened materials through atmospheric reaction in liquid metal deposition. ${ }^{[24]} \mathrm{Hu}$ et al. observed the size of oxide inclusion was influenced by the atmospheric oxygen level in an aluminum alloy. ${ }^{[25]}$ Shi et al also used LMD method to prepare blocks from pre-alloyed 9Cr-ODS powder and observed micro-sized large segregation of oxides. ${ }^{[26]}$

Though the potential of fabrication of ODS by AM was verified by the studies summarized above, the agglomeration/segregation of nanoinclusions remained as an obvious problem to solve in order to assure the adaption of AM for industry production. Other common problems encountered are the formation of defects, i.e., cracks and voids, and the coarsening of nanoinclusions during the SLM process of pre-alloyed ODS. Higher energy input in 
EBSM/LMD process may heal the cracks, improve the distribution of nanoinclusions and shorten the process time, however, this may still result lower strength and hardness due to the formation of macro defects and micro-sized agglomerations/precipitations. Furthermore, pre-alloying and ball milling are both time-consuming processes according to the present findings that may limit the industrial applications of AM ODS materials.

In our previous studies, the in-situ formation of Si-rich oxide nanoinclusions during laser melting of $316 \mathrm{~L}$ with $0.5 \mathrm{wt} \%$ of Si was observed. The in-situ formation of oxide nanoinclusions was also proved by many other studies lately. ${ }^{[27,28]}$ Good tensile strengths were achieved in samples with oxide nanoinclusions randomly distributed in the steel matrix. It indicated a possibility to fabricate ODS with improved mechanical properties by SLM. ${ }^{[29,30]}$ In this study, we report the results obtained in laser melting of a short time ball-milled mixture of $316 \mathrm{~L}$ steel and $\mathrm{Y}_{2} \mathrm{O}_{3}$ powder, including the influence of the amount of added $\mathrm{Y}_{2} \mathrm{O}_{3}(1 \mathrm{wt} \%$ and $2 \mathrm{wt} \%$ ) on properties of the final products, the detailed microstructure and the tensile strength measured at room temperature, $250{ }^{\circ} \mathrm{C}$ and $400{ }^{\circ} \mathrm{C}$, respectively.

\section{Experimental procedures}

\subsection{Fabrication process}

The procedure for preparing SLM ODS-316L is schematically illustrated in Fig. 1(a). The precursor powders were the gas atomized $316 \mathrm{~L}$ stainless steel powder containing $0.5 \mathrm{wt} \% \mathrm{Si}$ with size distributing from 10-45 $\mu \mathrm{m}$ (Fig. 1(b)) and the $\mathrm{Y}_{2} \mathrm{O}_{3}$ powder with an average particle size of $800 \mathrm{~nm}$ (Fig. 1(c)). The two powders were mixed with a nominal weight ratio 316L-1\% $\mathrm{Y}_{2} \mathrm{O}_{3}$ (ODS-1) and 316L-2\% $\mathrm{Y}_{2} \mathrm{O}_{3}$ (ODS-2) and milled by ball milling in PM 100 (Retsch, Haan, Germany) with a speed of $250 \mathrm{rpm}$ for $2 \mathrm{~h}$. Ethanol (99.5\%) was used during milling process to disperse and reduce agglomeration of the particles. WC balls were used as grinding media with a ball-to-powder ratio of 5:1. The mixed powders remain spherical shape with a similar size distribution, as shown in Fig. 1(d) and 1(e). Most of fine $\mathrm{Y}_{2} \mathrm{O}_{3}$ particles were found sticking on the steel particles whereas some forming also micro-sized agglomerates. The mixed powders were then consolidated by a SLM facility EOS M270 equipped with a continuous Yb-fiber laser with a maximum power of $200 \mathrm{~W}$ (EOS GmbH, Krailling, Germany), as shown in Fig. 1(f). The as-received 316L powder without addition of $\mathrm{Y}_{2} \mathrm{O}_{3}$ was also consolidated by SLM as a reference, referred as ODS-0. The process parameters for different powders were adjusted with the aim of achieving highest density. The performed experiments together with 
the obtained results are summarized in Table 1. The oxygen partial pressure in the processing chamber was kept below $1 \%$ during the SLM process. Cylinder samples with size of $\Phi 8 \times 50$ $\mathrm{mm}$ were prepared for the microstructure characterization and the mechanical tests, as seen in Fig. 1(g).

\subsection{Microstructure characterization}

Melt traces/pools were checked by optical microscopy (OM). Powder morphology, microstructure and fracture surface were characterized by field emission scanning electron microscopy (SEM, JSM-7000F, JEOL, Tokyo, Japan). The samples were mounted, polished and etched in diluted $\mathrm{HF}$ solution $\left(\mathrm{HF}: \mathrm{HNO}_{3}: \mathrm{H}_{2} \mathrm{O}=1: 4: 45\right)$ for 10 min prior to microstructure observation. The samples for transmission electron microscopy (TEM) analysis were prepared by mechanical polishing followed by electrochemical polishing using Struers TenuPol-5 Jet Polisher. The electrochemical polishing process is carried out at $-10{ }^{\circ} \mathrm{C}$ with a solution containing distilled water (9 vol\%), perchloric acid (7.8 vol\%), ethanol (73.1 vol\%) and butoxyethanol (10 vol\%). The Y content was analyzed by inductively coupled plasma optical emission spectrometry (ICP-OES). Small blocks of as-build samples were dissolved in warm diluted aqua regia $\left(\mathrm{HCl}: \mathrm{HNO}_{3}: \mathrm{H}_{2} \mathrm{O}=3: 1: 42\right)$ prior to ICP-OES. The chemical composition of the agglomerated clusters was checked by an energy dispersive X-ray spectroscopy (EDS) detector (Oxford Instruments, Oxford, UK) equipped on SEM.

\subsection{Physical and mechanical tests}

Densities of the fabricated samples were measured by Archimedes method and each sample was measured for 3 times. The tensile tests were performed at Shanghai Aeronautical Materials \& Structures Testing Co., LTD, Shanghai, China, at both room temperature according to ASTM E8 (RT, $22^{\circ} \mathrm{C}$ ) and elevated temperatures (ET, $250^{\circ} \mathrm{C}$ and $400^{\circ} \mathrm{C}$ ) according to ASTM E23. The as-build samples were machined to small-size standard cylinder tensile test samples as shown in Fig. 1(h) with a gauge length of $12 \mathrm{~mm}$ and cross-section of $\Phi 3 \mathrm{~mm}$. The strain rate is 0.015 before yielding and 0.05 after yielding at RT, and is 0.005 before yielding and 0.05 after yielding at elevated temperatures. The reported values of tensile properties in this study were the average value of 5 tests.

\section{Results and discussion}




\subsection{Composition and density}

The measured Y-content in the bulk samples are listed in Table 1. Loss of $\mathrm{Y}_{2} \mathrm{O}_{3}$ was obvious in both ODS-1 and ODS-2 after SLM process. $0.296 \%$ of $\mathrm{Y}_{2} \mathrm{O}_{3}$ was left in the bulk sample with nominal added $1 \%$ of $\mathrm{Y}_{2} \mathrm{O}_{3}$ steel powder while this amount increased to $0.374 \%$ in the sample with $2 \%$ of $\mathrm{Y}_{2} \mathrm{O}_{3}$ addition.

The SLM parameters for each sample were developed by aiming for achieving dense bulk with minimum power density $(w)$. The absorption of ND:YAG laser is above $60 \%$ in Fe-alloy powder while this is normally less than $6 \%$ in ceramic. ${ }^{[31]}$ Therefore, larger input energy density should be applied on steel powder covered with $\mathrm{Y}_{2} \mathrm{O}_{3}$ (Fig. 1(d)) than that on un-covered steel powder (Fig. 1(b)) to achieve the same consolidation behavior. The theoretical density of ODS samples can be calculated based on the following formula:

$$
\rho=\frac{\rho_{a} \rho_{b}}{\rho_{a} \cdot b \%+\rho_{b} \cdot a \%}
$$

where $\rho_{a}$ and $\rho_{b}$ are the density of SS316L $\left(8 \mathrm{~g} / \mathrm{cm}^{3}\right)$ and $\mathrm{Y}_{2} \mathrm{O}_{3}\left(5.01 \mathrm{~g} / \mathrm{cm}^{3}\right)$ and $a \%$ and $b \%$ are the weight percentage of SS316L and $\mathrm{Y}_{2} \mathrm{O}_{3}$. According to the chemical composition in Table 1, the calculated theoretical densities of ODS-1 and ODS-2 should be $7.986 \mathrm{~g} / \mathrm{cm}^{3}$ and 7.982 $\mathrm{g} / \mathrm{cm}^{3}$ respectively. The relative density of ODS -0 , ODS -1 and ODS-2 were thus calculated to be $99.3 \%, 99.4 \%$ and $99.4 \%$, implying similar density level was achieved in all three samples that was also further confirmed by the microstructure characterization (Fig. 2).

\subsection{Microstructure}

The SLM ODS-316L samples demonstrated a characteristic hierarchical microstructure consisting of melt traces/melt pools, grains, sub-grain cellular segregation/dislocation network and nanoinclusions, as shown in Fig. 2. The hatching distance was chosen so that the melt pools in all three samples (ODS-0, ODS-1 and ODS-2) overlapped in good condition leaving very few macro defects as shown in Fig. 2(a). Although the three samples were consolidated with different input energy density, no obvious difference on the size and shape of the melt pools was observed. The sub-grain cellular structure interfaced with $\mathrm{Cr}$ - and Mo-segregated boundaries was shown in Fig. 3(b). A lot of nanoinclusions (spherical black spots) were found randomly distributing both inside the cells and at the cell boundaries, as revealed in Fig. 3(c). There are more nanoinclusions appearing relatively coarser in ODS-1 and ODS-2 compared 
with ODS-0.

TEM analyses were carried out on ODS-1 to clarify the features of nanoinclusions. Electron diffraction pattern was taken along zone axis (01-1). It proved the phase formed in ODS-1 was mainly austenite. Bright-field (Fig. 3(a)) combined with Dark-field TEM (Fig. 3(b)) images clearly showed the fact that nanoinclusions with size of several tens of nanometers distributing evenly in the steel matrix. A few large precipitates (several hundred nanometers) were observed, as shown in Fig. 3(c), which turned to be agglomerations of several smaller inclusions at high resolution. EDS mapping result shown in Fig. 3(e) proved that the nanoinclusions are rich in Y. Furthermore, two kinds of spherical nanoinclusions were identified as seen in Fig. 4(f): one with brighter contrast and the other with dark contrast. EDS analysis revealed that the brighter one had a Y/Si weight ratio of 2 while the dark one has a Y/Si weight ratio of 0.5. The size distribution of nanoinclusions shown in Fig. 3(d) was obtained by counting more than 300 nanoinclusions from randomly chosen 10 pieces of TEM images. The dominant size range is in the range of 10 to $70 \mathrm{~nm}$, much smaller than that of the precursor $\mathrm{Y}_{2} \mathrm{O}_{3}(800 \mathrm{~nm})$. The size of nanoinclusions obtained in this study shows little difference with previous studies using $40 \mathrm{~nm}$ ceramic precursor powders. ${ }^{[18,23]}$ No severe precipitations or agglomeration of nanoinclusions existed in the bulk section (away from surface) of samples ODS-0 and ODS-1 while some micro-sized agglomerations were traced in sample ODS-2.

\subsection{Mechanical properties}

Fig. 4 shows the engineering stress-strain curves at different temperatures (room temperature (RT), $250{ }^{\circ} \mathrm{C}$ and $400{ }^{\circ} \mathrm{C}$ ) of ODS-0, ODS-1 and ODS-2. Yield strength of 552 $\mathrm{MPa}$ and elongation at rupture of $83.2 \%$ at RT were observed in the sample ODS- 0 . In a previous study it was shown that the high strength of ODS-0 could be attributed to the formation of cellular segregation/dislocation network and the nanoinclusions. ${ }^{[32]}$ In this study, the increased amount of oxide nanoinclusions introduced more dislocation pinning sites and thus further improved the yield strength. The highest yield strength of $574 \mathrm{MPa}$ and elongation at rupture of $90.5 \%$ were achieved in the sample ODS-1. Both strength and ductility of this sample are better than those of the sample ODS-0. However, excessive addition of $\mathrm{Y}_{2} \mathrm{O}_{3}$ did not seem to further improve strength, as revealed by the yield strength of $553 \mathrm{MPa}$ and elongation of $95.7 \%$ achieved in the sample ODS-2. It may be concluded that there appears an upper limit of additional $\mathrm{Y}_{2} \mathrm{O}_{3}$ powder for achieving good dispersion due to the capability of Marangoni 
convection and the recoil force in the melt pool, which requires further investigation to identify. It is worth noticing that both samples ODS-1 and ODS-2 exhibit relative less increase of engineering stress after entering plastic deformation region (a flat curve after yield point) while its counterpart without $\mathrm{Y}_{2} \mathrm{O}_{3}$ addition has a larger increase of engineering stress.

At ET, all the ODS samples still kept their high strength but their elongation dropped dramatically. The sample ODS-0 revealed yield strength of $431 \mathrm{MPa}, 389 \mathrm{MPa}$ and elongation of $33.3 \%$ and 38.3 at $250^{\circ} \mathrm{C}$ and $400^{\circ} \mathrm{C}$, respectively. Increased yield strength of $456 \mathrm{MPa}$ and $420 \mathrm{MPa}$ but reduced elongation of $28.7 \%$ and $29.3 \%$ at $250^{\circ} \mathrm{C}$ and $400^{\circ} \mathrm{C}$, respectively, were obtained in the sample ODS-1. The mechanical properties of the sample ODS-2 are similar to those of the sample ODS-1, with the yield strength of $440 \mathrm{MPa}$ and $405 \mathrm{MPa}$ and elongation of $29.9 \%$ and $37.4 \%$ at $250^{\circ} \mathrm{C}$ and $400^{\circ} \mathrm{C}$, respectively.

Similar to the trend at observed at RT, the sample ODS-1demonstrated the highest strength among all these three samples.

\subsection{Fractography of ODS-1 at different temperatures}

The fractographic photos taken on the sample ODS- 1 after testing at RT, $250^{\circ} \mathrm{C}$ and $400^{\circ} \mathrm{C}$, respectively, are shown in Fig. 5. At RT, the sample had much longer elongation than at ET (Fig. 5(a)) and the small holes observed on the fracture surface revealed a discrete feature (indicated by the solid arrow in Fig. 5(b)). At ET, several larger craters were observed that seemed to form by the coalescence of some macro-holes (hollow arrows, Fig. 5(b)). In addition, the side view of the fracture tip revealed the presence of macro-voids at the necking area in the samples after testing at ET (hollow arrow, Fig. 5(c)) while only fewer smaller voids were observed in the samples after testing at RT. The inserted image proved that the small void observed in the samples after testing at RT was initiated at the site of a large micro-sized inclusion. The size of this void was well confined to be less than $10 \mu \mathrm{m}$. It is thus reasonable to conclude that the small discrete holes in the samples after testing at RT were formed due to the presence of some micro-sized inclusions. The fracture of the samples after testing at RT appeared not to be caused by the coalescence of these smaller holes, because they showed a clear discrete feature. On the other hand, the observation of clear fracture lines in the samples after testing at ET indicated that here the fracture was caused by the coalescence of the larger micro-voids.

\section{Discussion}




\subsection{Oxide distribution behavior and the loss of $\mathrm{Y}_{2} \mathrm{O}_{3}$}

Complex chemical/physical activities were stimulated inside the melt pools during SLM process. In the samples ODS-1 and ODS-2, the alloying element silicon presented in 316L powder reacted with $\mathrm{Y}_{2} \mathrm{O}_{3}$ melt and formed ( $\mathrm{Si}, \mathrm{Y}, \mathrm{O}$ )-rich nanoinclusions as proved in Fig. 4(f). Two factors had influence on the dispersion behavior of the nanoinclusions, which were the melt flow inside the melt pools and the solidification rate of the melt pools. $\mathrm{Y}_{2} \mathrm{O}_{3}$ powder was believed to be melted during SLM process as indicated by the fact that most nanoinclusions were spherical shaped and differed from their original flake-like shape (Fig. 1). The melted $\mathrm{Y}_{2} \mathrm{O}_{3}$ droplets moved together with the melt pool flow. The flow behaviors were mainly determined by the Marangoni force and the recoil pressure. The large $\mathrm{Y}_{2} \mathrm{O}_{3}$ agglomerations were splashed into smaller droplets by the Marangoni convection flow, the recoil pressure and the immediate impact of the laser beam. This phenomenon of relocating and regulating the precipitated secondly phases by the liquid capillary force induced by the Marangoni effect in the melt pool was widely discussed when additive manufacturing process was applied to prepare metal matrix composites $(\mathrm{MMC})^{[33,34]}$. It is reasonable to predict that stronger melt pool convection can better break the larger droplets and disperse the nanoinclusions more evenly in the steel matrix. Meanwhile, the flowing melt pools solidified at a rather rapid speed in the order of $10^{6} \mathrm{~K} / \mathrm{s}$ and frozen the nanoinclusions fast enough to avoid their further coarsening and agglomeration. ${ }^{[35]}$ The combined effect of the convective melt pool flow and the rapid solidification are thus a key factor ensuring successful SLM process of ODS 316L parts.

The laser scanning speed $(v)$ plays a leading role in determining both the convective flow and the solidification rate. With the same energy density, a higher v would generate smaller melt pools thus a faster solidification rate ${ }^{[36,37]}$ although full understanding of the influence of $\mathrm{v}$ is still in debate ${ }^{[35,38,39]}$ The dispersion behavior influenced by different $v(600 \mathrm{~mm} / \mathrm{s}(\mathrm{a}), 800$ $\mathrm{mm} / \mathrm{s}$ (b) and $1200 \mathrm{~mm} / \mathrm{s}$ (c)) was investigated in the sample ODS-1 (Fig. 6). A schematic draw illustrating the dispersion behavior in a melt pool is also shown in Fig. 6(e). Agglomerations tended to float and agglomerate on the top of a single melt pool due to the lower density of the oxides compared to the steel matrix (Fig. 6(a)). A higher v could successfully relieve this phenomenon (Fig. 6(b, c)). The reason is that a longer solidification time at lower $\mathrm{v}$ gave more time for the oxides to agglomerate and to form a layer of oxide clusters floating on the top of a melt pool. As shown in Fig. 6(e), a layer of oxide clusters did form at the interface between a 
single melt pool and the base material (see the yellow region). The melt pool boundaries adjacent to the base material solidified first due to the fast heat transfer. Simulation results also proved the Marangoni convection near the melt pool boundaries were relative weaker than that in the inner part ${ }^{[40]}$. Therefore, the $\mathrm{Y}_{2} \mathrm{O}_{3}$ clusters had not enough time and driving force to be dispersed and thus remained as some clusters at the melt pool boundaries. The strong convection inside the melt pool (green region) was on the other hand able to break and disperse the oxide agglomerations. This fact opens up an opportunity to relocate the formed clusters (the yellow region in Fig 6(e)) at the last melt trace by the overlapping re-melting from the new adjacent melt trace (the green region in Fig. 6(e)). In this case, the hatch spacing $(d)$ should be small enough to achieve an even dispersion. On the other hand, although higher v introduced stronger convection, the resulting lower w might deteriorate the densification behavior and left some large particle-porosity clusters ${ }^{[41]}$. A good balance between the stronger melt convection and the enough energy input should be achieved by applying a proper $v$. It is worth noticing that it was impossible to fully prevent the floating of oxide clusters to the melt pool surface under our experimental conditions, so the loss of $\mathrm{Y}_{2} \mathrm{O}_{3}$ was inevitable. A higher power laser that can densify the material with a higher speed might be able to totally remove these oxide clusters.

Previous investigations concluded that the smaller inclusions tended to grow and collide into larger particles ${ }^{[25]}$ and they could even dissolve and diffuse to the grain boundary to form larger precipitates ${ }^{[28]}$. A higher concentration of environmental oxygen was also believed to coarser the nanoinclusions' size ${ }^{[42]}$. The higher amount of oxides added in ODS-2 thus facilitated the growth, collision and diffusion of smaller oxides and larger oxides were reasonable to be formed. Moreover, the capacity of the melt pool convection also limited the even distribution behavior when the amount of oxides increased, as in the case of ODS-2. This means that the larger oxide melt droplets in the sample ODS-2 was not able to be broken down to smaller oxide clusters as those observed in the sample ODS-1, instead, they would easily collide and agglomerate. Due to these reasons, the average size of the nanoinclusions in the sample ODS-2 was larger and the formation of large agglomeration of oxides in the sample ODS-2 appeared inevitable (Fig. 2(c)).

\subsection{Typical necking mechanism in SLM ODS $316 \mathrm{~L}$}

One interesting feature of SLM ODS 316L steels is the observed combination of a rather high ductility with such high yield strength. As revealed by Fig. 7, the true stress-strain curve showed the strain hardening rate of all three samples recovered gradually during the tests and 
delayed the necking process, which resulted in a high uniform elongation and total elongation. Some recent publications explained that the high ductility is due to the cellular dislocation network and the nanoinclusions that provided enough sites for deformation twinning and dislocation pinning/delaying. ${ }^{[32,43-48]}$ In this study, the addition of extra $\mathrm{Y}_{2} \mathrm{O}_{3}$ in the sample ODS-1 further improved both the strength and ductility of SLM 316L. It is observed that the nanoinclusions and the suppressed growth of related voids contributed to the better ductility. Many nano-voids were observed growing in the whole gauge length area instead of just in the local necking area before necking started, which was proved by the elongated voids at the non-necking area in Fig. 8(a). The large tensile stress formed owing to the deformation incompatibility between the nano-inclusion and steel matrix that in turn induced interfacial decohesion and formed those elongated voids, which was proved by the inserted image in Fig. 8(a). Large amount of the evenly distributed nano-voids relieved the tensile stress and further prevented high stress concentration in local area, which otherwise would triggered the necking, micro-voids linkage and finally fracture. Furthermore, the growth of these evenly distributed nano-voids was suppressed by the nanostructured segregation of cell boundaries as indicated by the arrows in Fig. 8(c). It appeared that the voids linkage could only occur when the stress became large enough to break the segregated cell boundaries. In this way, instead behaving as crack propagation paths like the grain boundaries, the cell boundaries would suppress the crack propagation jointly with nanoinclusions. This mechanism is different from that observed in conventionally fabricated materials as summarized in Fig. 8(d). In conventional theory, necking would progress rapidly after voids generation followed by voids growth and coalescence. The strain hardening rate decreased slowly at the beginning but suddenly dropped dramatically after the necking due to the appearance of macroscopic voids and the high concentration of stress. Furthermore, the nanoinclusions with size around $70 \mathrm{~nm}$ were proved to serve dual purposes of blocking and storing of dislocations, resulting work hardening. ${ }^{[49]}$ This resulted in the higher strain hardening rate recovery observed in the sample ODS-1 with more nanoinclusions and explained why better ductility with higher yield strength was achieved compared with the sample ODS-0. In a recent study, it was proved that nanoinclusions inhibited radiation-induced swelling while dislocations promoted it. ${ }^{[50]}$ Therefore, the addition of extra nanoinclusions is expected to increase the anti-swelling property of AM stainless steel. Nevertheless, another study concluded that finer oxide nanoinclusions with an average size of $7.5 \mathrm{~nm}$ contributed mostly to strength improvement. ${ }^{[5]}$ It has also been proved that large oxide inclusions $(>100$ $\mathrm{nm}$ ) would greatly deteriorate the impact toughness of AM stainless steels via promoting early initiation of micro voids. ${ }^{[51]}$ Future work should be focused on how to achieve finer oxide 
nanoinclusions with size smaller than $10 \mathrm{~nm}$.

Similar mechanism was also observed recently in TWIP steels. Macro-voids were found distributing densely throughout the whole gauge section and the sudden drop of strain hardening rate just before necking was attributed to the coalescence of these macro-voids. ${ }^{[52]}$ Our study may provide a way to further increase the ductility of TWIP steels -by simultaneously introducing nanoinclusions and nanostructured segregation network.

At ET, the necking mechanism was similar to that has been observed in the conventional materials. No nano-void nucleation and growth was observed in the non-necking section as seen in Fig. 8(b). The strain hardening rate dropped below the true stress level shortly after yielding and trigged the necking process. It is worth noticing that the strain hardening rate still recovered a bit even after necking, which should be attributed to the presence of both the cellular network and the nanoinclusions. However, the coalescence of the already grown macro-voids at the necking section fractured the sample even if the work hardening slightly delayed the fracture process.

\section{Conclusions}

1. Coarse $\mathrm{Y}_{2} \mathrm{O}_{3}$ powder can be used for preparing of oxide dispersion strengthened (ODS) 316L steels with finer nanoinclusions evenly distributed inside the metal matrix by SLM processing of ball milled powder mixtures.

2. Optimizing the process parameters can balance the densification behavior and the dispersion of nanoinclusions. Even dispersion of nanoinclusions rich in $\mathrm{Si}, \mathrm{Y}$ and $\mathrm{O}$ with several tens of nanometers in size can be achieved in $1 \%$ addition of $\mathrm{Y}_{2} \mathrm{O}_{3}$, whereas the excessive addition of $\mathrm{Y}_{2} \mathrm{O}_{3}$ is limited by the capacity of the melt pool convection.

3. The added oxide nanoinclusions improve both the strength and ductility of $316 \mathrm{~L}$ stainless steel, resulting ODS 316L stainless steel with yield strength of $574 \mathrm{MPa}$ and elongation of $91 \%$ at RT when $1 \%$ of $\mathrm{Y}_{2} \mathrm{O}_{3}$ is added. High elongation is achieved due to the stable recovery of strain hardening rate. At ET, the high strength is kept, but the ductility drops dramatically.

4. Nano-voids nucleate at the sites of the nanoinclusions throughout the whole gauge length area. Their growth and coalescence are suppressed by the formed cellular segregation 
network inside individual grains. The combinational effect of the nanoinclusions and the dislocation/segregation network readily relieves the stress concentration and delays the necking process in addition to the dislocation pinning and the deformation twinning.

5. It should be noted that although the addition of $\mathrm{Y}_{2} \mathrm{O}_{3}$ improved the mechanical behavior in this study, there is still space for further improvement by refining the size of the nanoinclusions. 


\section{References}

[1] M. Phaniraj, D.I. Kim, J.H. Shim, Y.W. Cho, Acta Mater. 57(6) (2009) 1856-1864.

[2] X. Mao, K.H. Oh, J. Jang, Mater. Charact. 117 (2016) 91-98.

[3] K. Suresh, M. Nagini, R. Vijay, M. Ramakrishna, R.C. Gundakaram, A. Reddy, G. Sundararajan, Mater. Des. 110 (2016) 519-525.

[4] W. Man, Z. Zhangjian, Y. Zhigang, Y. Pengfei, S. Hongying, Acta Metall Sin 49(2) (2013) 153-158.

[5] Y. Miao, K. Mo, Z. Zhou, X. Liu, K.C. Lan, G. Zhang, M.K. Miller, K.A. Powers, Z.G. Mei, J.S. Park, Mater. Sci. Eng. A 639 (2015) 585-596.

[6] S. Ukai, M. Harada, H. Okada, M. Inoue, S. Nomura, S. Shikakura, K. Asabe, T. Nishida, M. Fujiwara, J. Nucl. Mater. 204 (1993) 65-73.

[7] S. Ukai, M. Fujiwara, J. Nucl. Mater. 307 (2002) 749-757.

[8] R. Lindau, M. Klimenkov, U. Jäntsch, A. Möslang, L. Commin, J. Nucl. Mater. 416(1) (2011) 22-29.

[9] J.-P. Kruth, L. Froyen, J. Van Vaerenbergh, P. Mercelis, M. Rombouts, B. Lauwers, J. Mater. Process.Technol. 149(1) (2004) 616-622.

[10] Y. Zhong, L.-E. Rännar, S. Wikman, A. Koptyug, L. Liu, D. Cui, Z. Shen, Fusion Eng. Des. 116 (2017) 24-33.

[11] J. Yang, Y. Wang, F. Li, W. Huang, G. Jing, Z. Wang, X. Zeng, J. Mater. Sci. Technol. 35(9) (2019) 1817-1824.

[12] D. Gu, H. Wang, D. Dai, P. Yuan, W. Meiners, R. Poprawe, Scr. Mater. 96 (2015) 25-28.

[13] B. AlMangour, D. Grzesiak, J.M. Yang, Mater. Des. 96 (2016) 150-161.

[14] I. Segura, L. Murr, C. Terrazas, D. Bermudez, J. Mireles, V. Injeti, K. Li, B. Yu, R. Misra, R. Wicker, J. Mater. Sci. Technol. 35(2) (2019) 351-367.

[15] D. Wang, C. Chi, W. Wang, Y. Li, M. Wang, X. Chen, Z. Chen, X. Cheng, Y. Xie, J. Mater. Sci. Technol. 35(7) (2019) 1315-1322.

[16] J.C. Walker, K.M. Berggreen, A.R. Jones, C.J. Sutcliffe, Adv. Eng. Mater. 11(7) (2009) 541-546.

[17] R.M. Hunt, K.J. Kramer, B. El-Dasher, J. Nucl. Mater. 464 (2015) 80-85.

[18] H.J. Chang, H.Y. Cho, J.H. Kim, J. Alloys Compd. 653 (2015) 528-533.

[19] E. Vasquez, P.-F. Giroux, F. Lomello, A. Chniouel, H. Maskrot, F. Schuster, P. Castany, J. Mater. Process. Technol. 267 (2019) 403-413.

[20] T. Boegelein, S.N. Dryepondt, A. Pandey, K. Dawson, G.J. Tatlock, Acta Mater. 87 (2015) 201-215.

[21] T. Boegelein, E. Louvis, K. Dawson, G.J. Tatlock, A.R. Jones, Mater. Charact. 112 (2016) 30-40.

[22] Y. Zhang, J. Zhang, Q. Yan, L. Zhang, M. Wang, B. Song, Y. Shi, Scr. Mater. 148 (2018) 20-23.

[23] R. Gao, L. Zeng, H. Ding, T. Zhang, X. Wang, Q. Fang, Mater. Des. 89 (2016) 1171-1180.

[24] H. Springer, C. Baron, A. Szczepaniak, E. Jägle, M. Wilms, A. Weisheit, D. Raabe, Mater. Des. 111 (2016) 60-69.

[25] Z. Hu, H. Zhu, X. Nie, C. Zhang, H. Zhang, X. Zeng, Mater. Des.150 (2018) 18-27.

[26] Y. Shi, Z. Lu, H. Xu, R. Xie, Y. Ren, G. Yang, J. Alloys Compd. 791 (2019) 121-133.

[27] T.H. Hsu, Y.J. Chang, C.Y. Huang, H.W. Yen, C.P. Chen, K.K. Jen, A.C. Yeh, J. Alloys Compd. 803 (2019) $30-41$.

[28] C. Qiu, J. Alloys Compd. 790 (2019) 1023-1033.

[29] Y. Zhong, L. Liu, S. Wikman, D. Cui, Z. Shen, J. Nucl. Mater. 470 (2016) 170-178.

[30] K. Saeidi, L. Kvetková, F. Lofaj, Z. Shen, RSC Adv. 5(27) (2015) 20747-20750.

[31] J.-P. Kruth, X. Wang, T. Laoui, L. Froyen, Assembly Automation 23(4) (2003) 357-371.

[32] L. Liu, Q. Ding, Y. Zhong, J. Zou, J. Wu, Y.L. Chiu, J. Li, Z. Zhang, Q. Yu, Z. Shen, Mater. Today 21(4)

(2018) 354-361.

[33] B. AlMangour, D. Grzesiak, J.M. Yang, J. Alloys Compd. 680 (2016) 480-493.

[34] H. Zhang, D. Gu, L. Xi, H. Zhang, M. Xia, C. Ma, J. Mater. Sci. Technol. 35(6) (2019) 1128-1136.

[35] P. Yuan, D. Gu, D. Dai, Mater. Des. (82) (2015) 46-55. 
[36] I. Yadroitsev, P. Krakhmalev, I. Yadroitsava, S. Johansson, I. Smurov, J. Mater. Process.Technol. 213(4) (2013) 606-613.

[37] S. Kou, Welding Metallurgy, Second ed. New York, 1987..

[38] D. Gu, Y.-C. Hagedorn, W. Meiners, K. Wissenbach, R. Poprawe, Compos. Sci. and Technol. 71(13) (2011) 1612-1620.

[39] C. Qiu, C. Panwisawas, M. Ward, H.C. Basoalto, J.W. Brooks, M.M. Attallah, Acta Mater. 96 (2015) 72 -79. [40] S.A. Khairallah, A.T. Anderson, A. Rubenchik, W.E. King, Acta Mater. 108 (2016) 36-45.

[41] P. Bindumadhavan, T. Chia, M. Chandrasekaran, H.K. Wah, L.N. Lam, O. Prabhakar, Mater. Sci. Eng. A 315(1) (2001) 217-226.

[42] D.R. Eo, S.H. Park, J.W. Cho, Mater. Des. 155 (2018) 212-219.

[43] Y.M. Wang, T. Voisin, J.T. McKeown, J. Ye, N.P. Calta, Z. Li, Z. Zeng, Y. Zhang, W. Chen, T.T. Roehling, Nat. Mater. 17(1) (2018) 63.

[44] Z. Sun, X. Tan, S.B. Tor, C.K. Chua, NPG Asia Mater. 10(2018) 127-136.

[45] F. Yan, W. Xiong, E. Faierson, G.B. Olson, Scr. Mater. 155 (2018) 104-108.

[46] Q. Nguyen, Z. Zhu, F. Ng, B. Chua, S. Nai, J. Wei, J. Mater. Sci. Technol. 35(2) (2019) 388-394.

[47] R. Casati, J. Lemke, M. Vedani, J. Mater. Sci. Technol. 32(8) (2016) 738-744.

[48] D. Kong, C. Dong, X. Ni, L. Zhang, J. Yao, C. Man, X. Cheng, K. Xiao, X. Li, J. Mater. Sci. Technol. 35(7) (2019) 1499-1507.

[49] G. Liu, G. Zhang, F. Jiang, X. Ding, Y. Sun, J. Sun, E. Ma, Nat. Mater. 12(4) (2013) 344.

[50] G.M. de Bellefon, K. Bertsch, M. Chancey, Y. Wang, D. Thoma, J. Nucl. Mater. 523 (2019) $291 \mathrm{e} 298$.

[51] X. Lou, P.L. Andresen, R.B. Rebak, J. Nucl. Mater. 499 (2018) 182-190.

[52] C. Yang, Z. Zhang, P. Zhang, Z. Zhang, Acta Mater. 136 (2017) 1-10. 


\section{Figure and table captions}

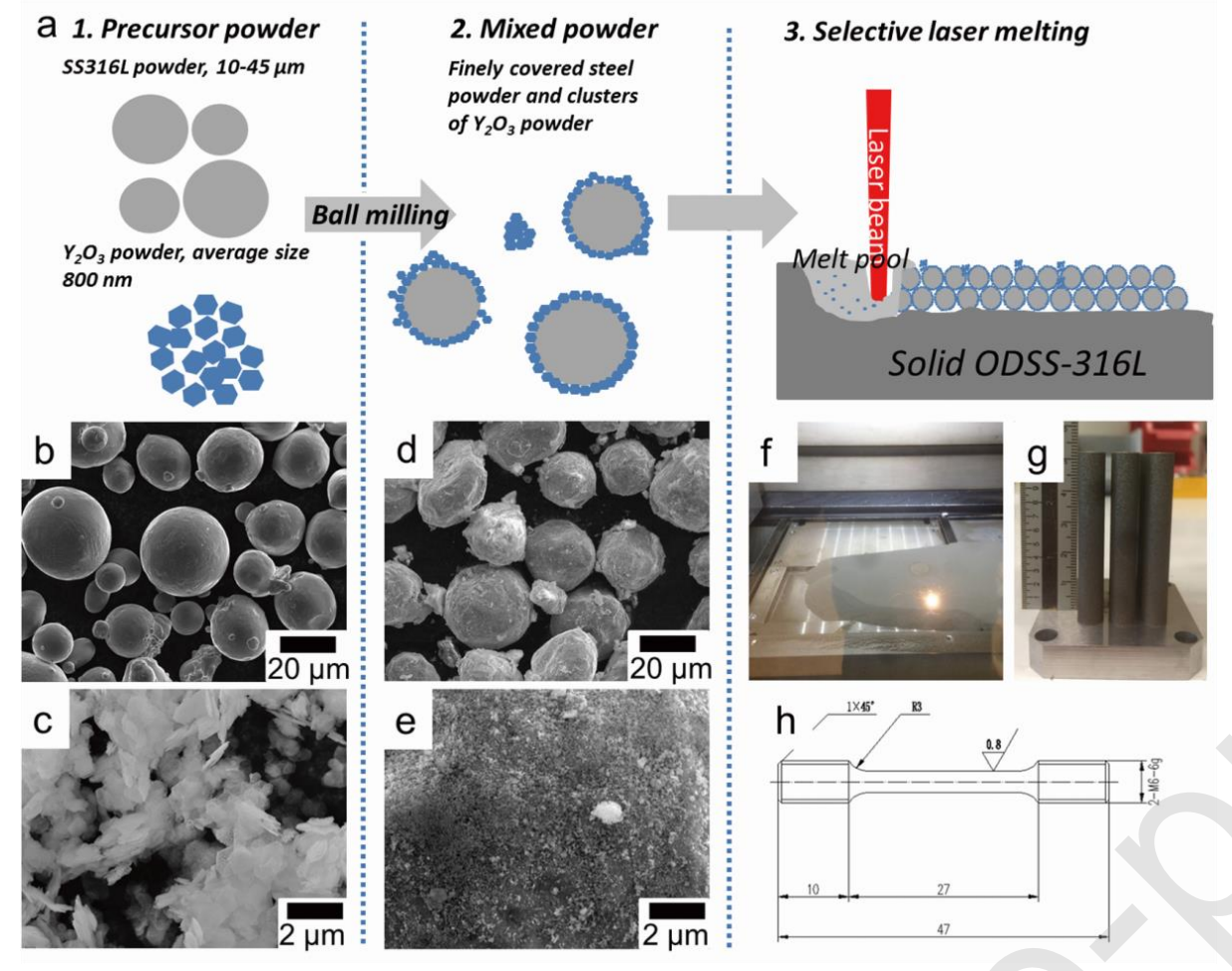

Fig. 1. Workflow for preparing ODS by SLM (a); SEM images of the precursor 316L steel powder (a), precursor $\mathrm{Y}_{2} \mathrm{O}_{3}$ powder (b) ball milled powder mixture at low magnification (c) and high magnification (d); SLM process of powder mixture (f), consolidated ODS -316L (g) and shape of tensile test samples (h).
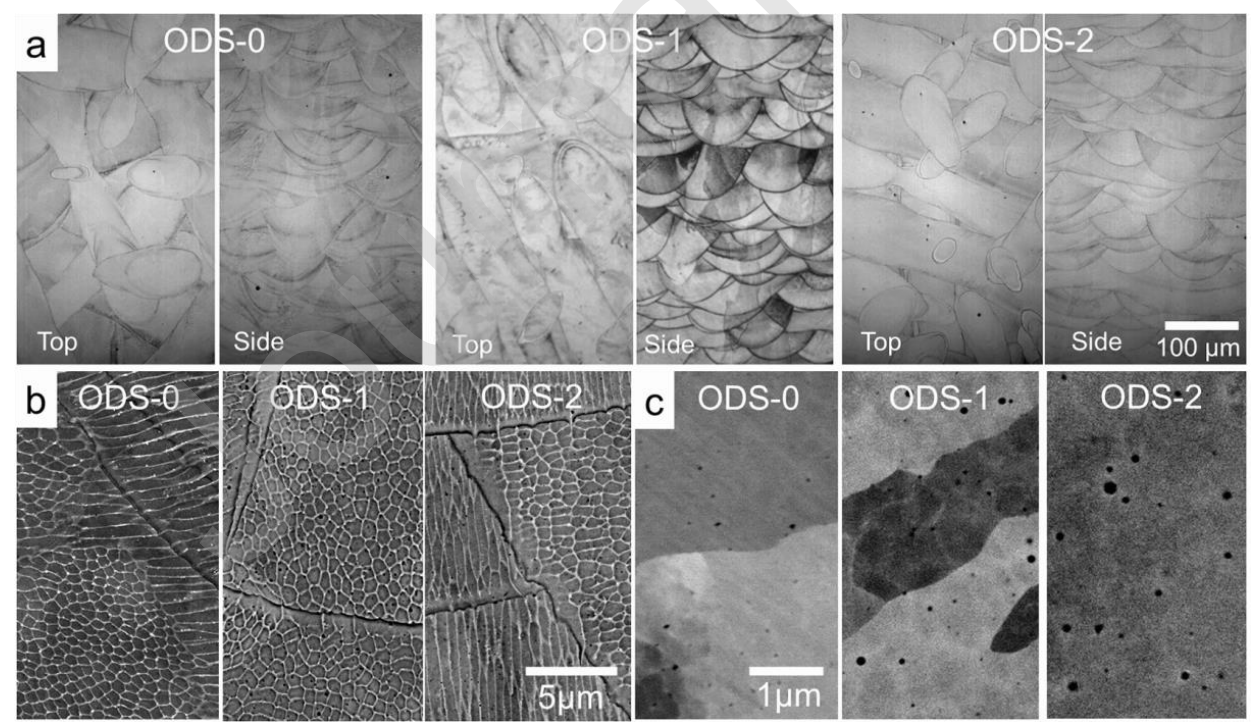

Fig. 2. Microstructure of ODS-0, ODS-1 and ODS-2, respectively: OM images of the melt pools with top view and side view (a), SEM image of the etched surfaces revealing cellular segregation network (b) and finely polished surface revealing nanoinclusions (c). 

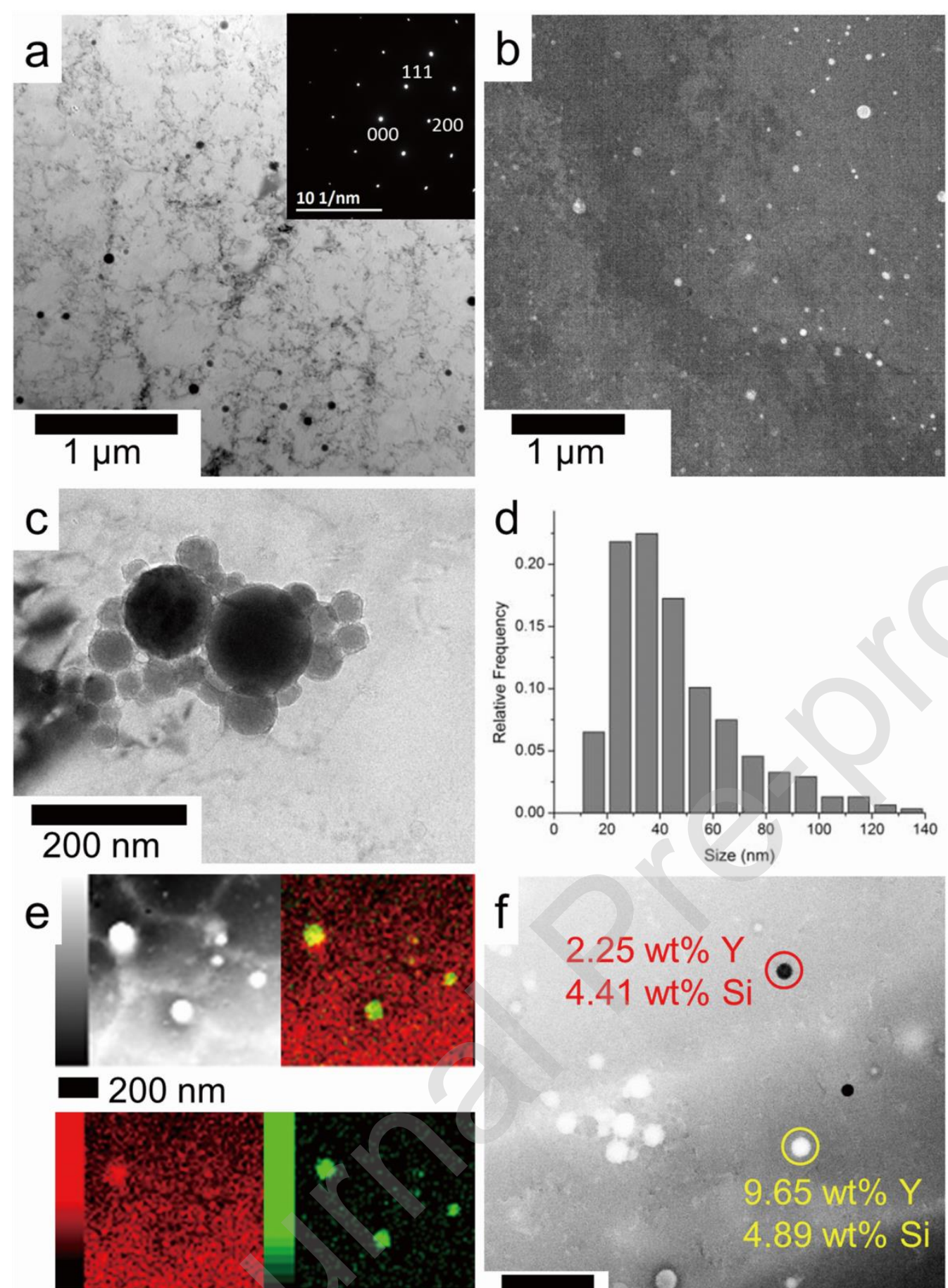

$\mathrm{Fe}$ Y $200 \mathrm{~nm}$

Fig. 3. TEM characterization of the nanoinclusions in the sample ODS-1: BFTEM (a) and DFTEM (b) images, the selected area diffraction pattern was inserted in (a), BFTEM image showing agglomeration of nanoinclusions (c), calculated size distribution of oxide inclusions (d), TEM EDS mapping on several large nanoinclusions (e), EDS results on two nanoinclusions with different compositions (f). 


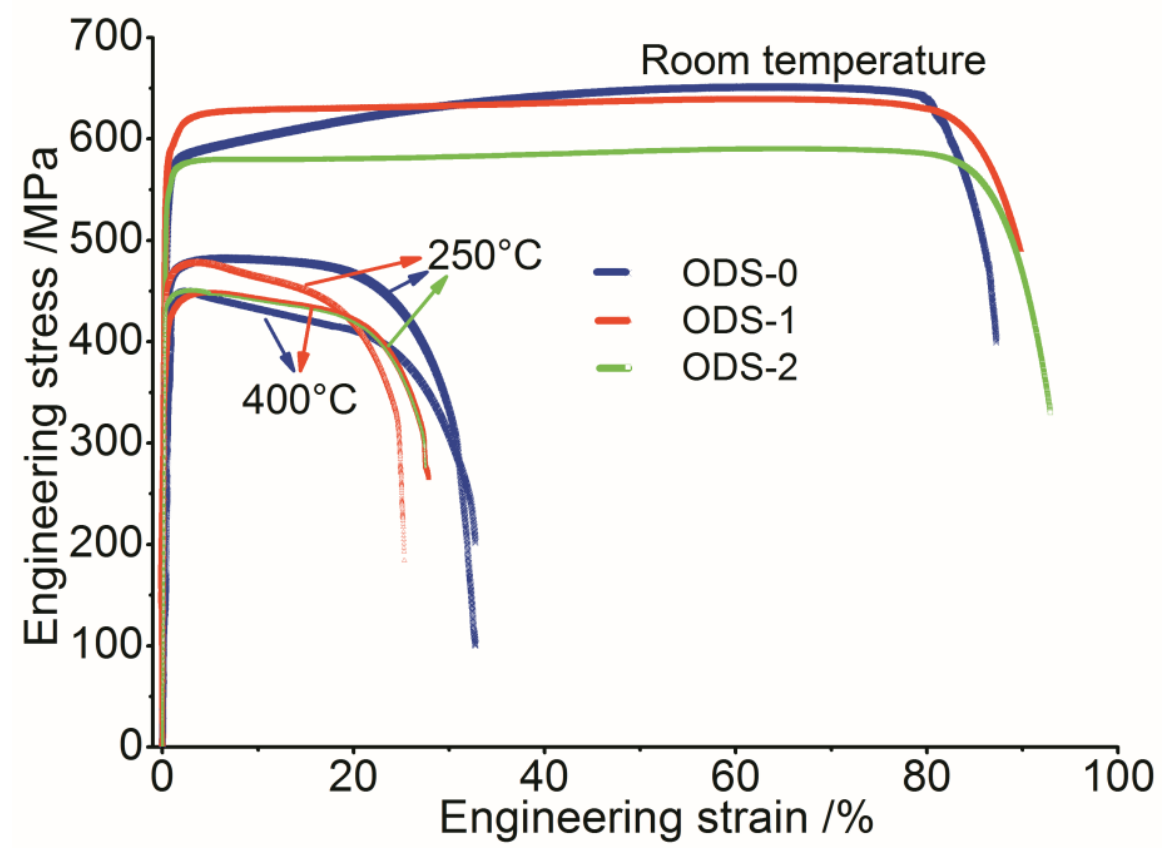

Fig. 4. Engineering stress-strain curves of the samples ODS-0, ODS-1 and ODS-2 at different temperatures.

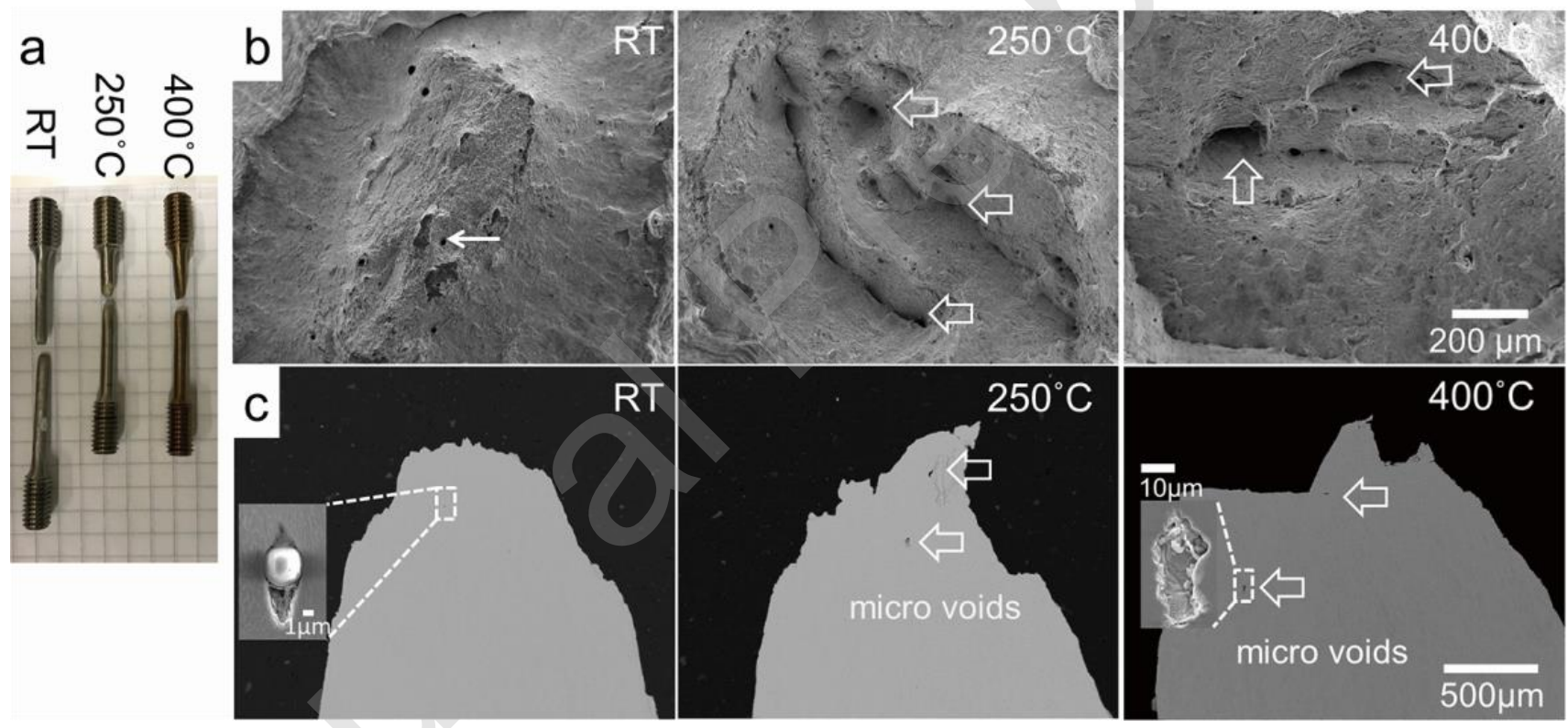

Fig. 5. Tensile behaviors tested at different temperatures of the sample ODS-1 (a), SEM images of fracture surface at different temperature (b), side view of fracture tip at different temperatures with inserted images revealing the large micro-size voids (c). 

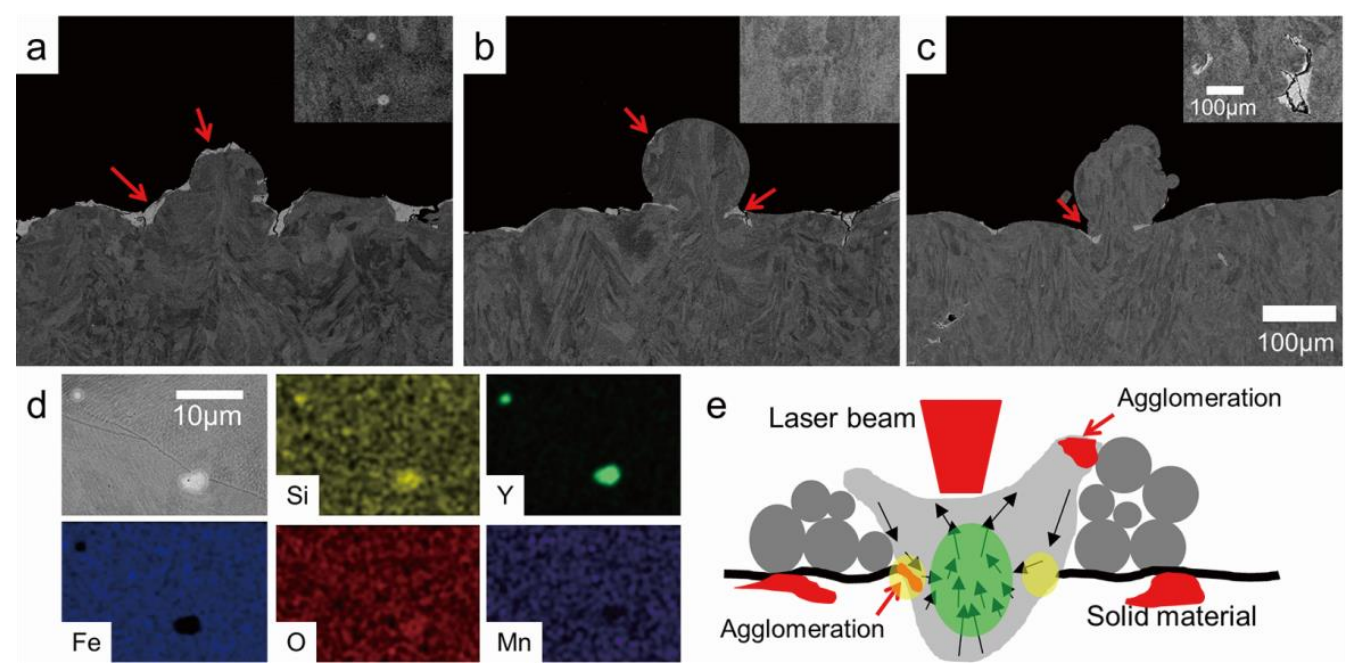

Fig. 6. Agglomerations of nanoinclusions in the sample ODS-1 in a single melt trace with

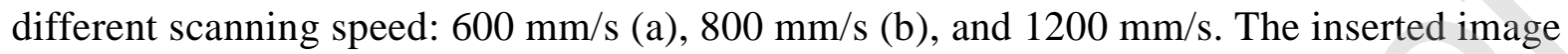
shows the agglomeration behavior in the bulk material away from the top surface. EDS mapping of some agglomerations (d) and a schematic drawing of the agglomeration formation in a melt pool (e).

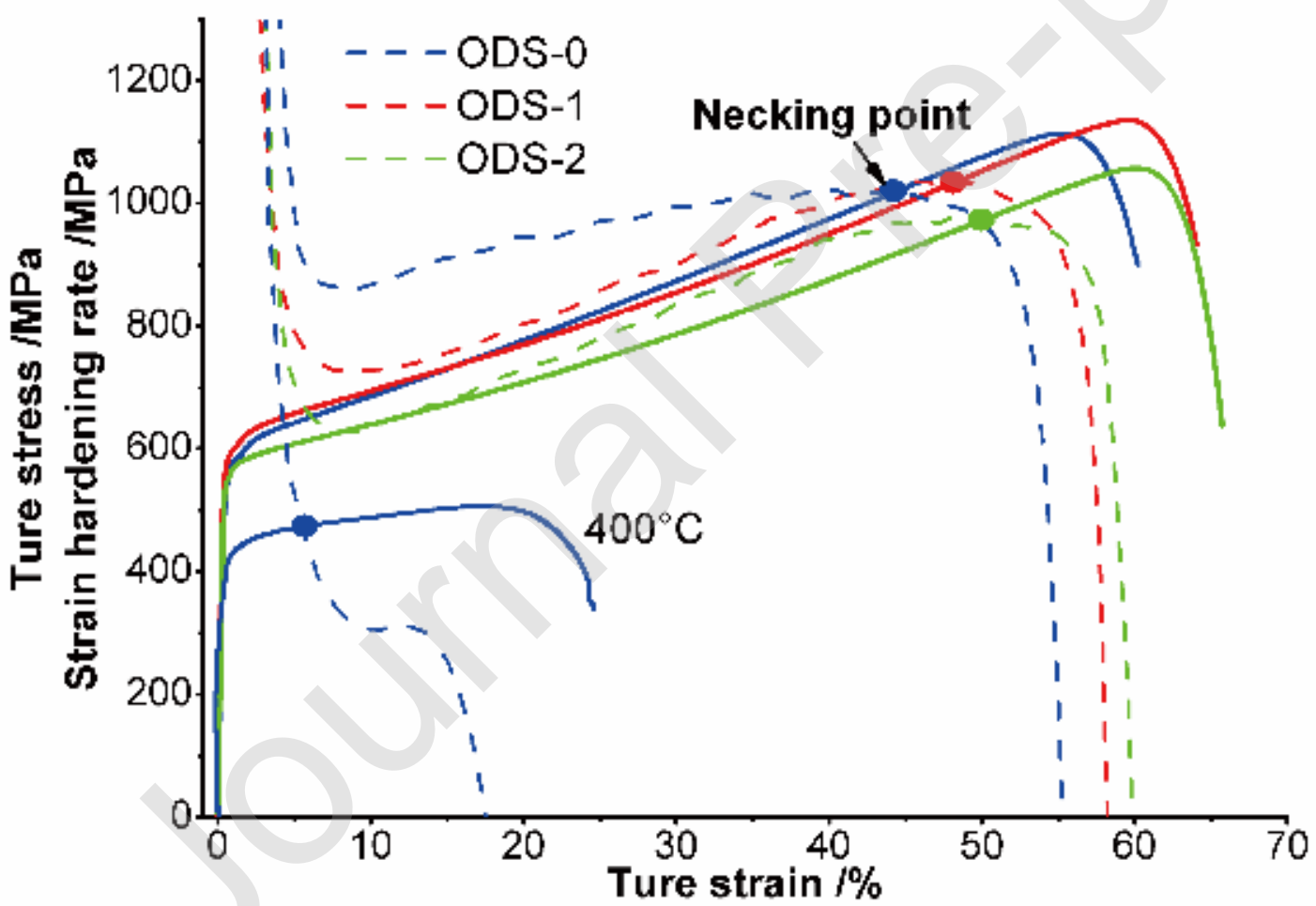

Fig. 7. True-stress strain curve (solid line) versus the strain hardening rate curve (dashed line) of different SLM ODS 316L steels. 

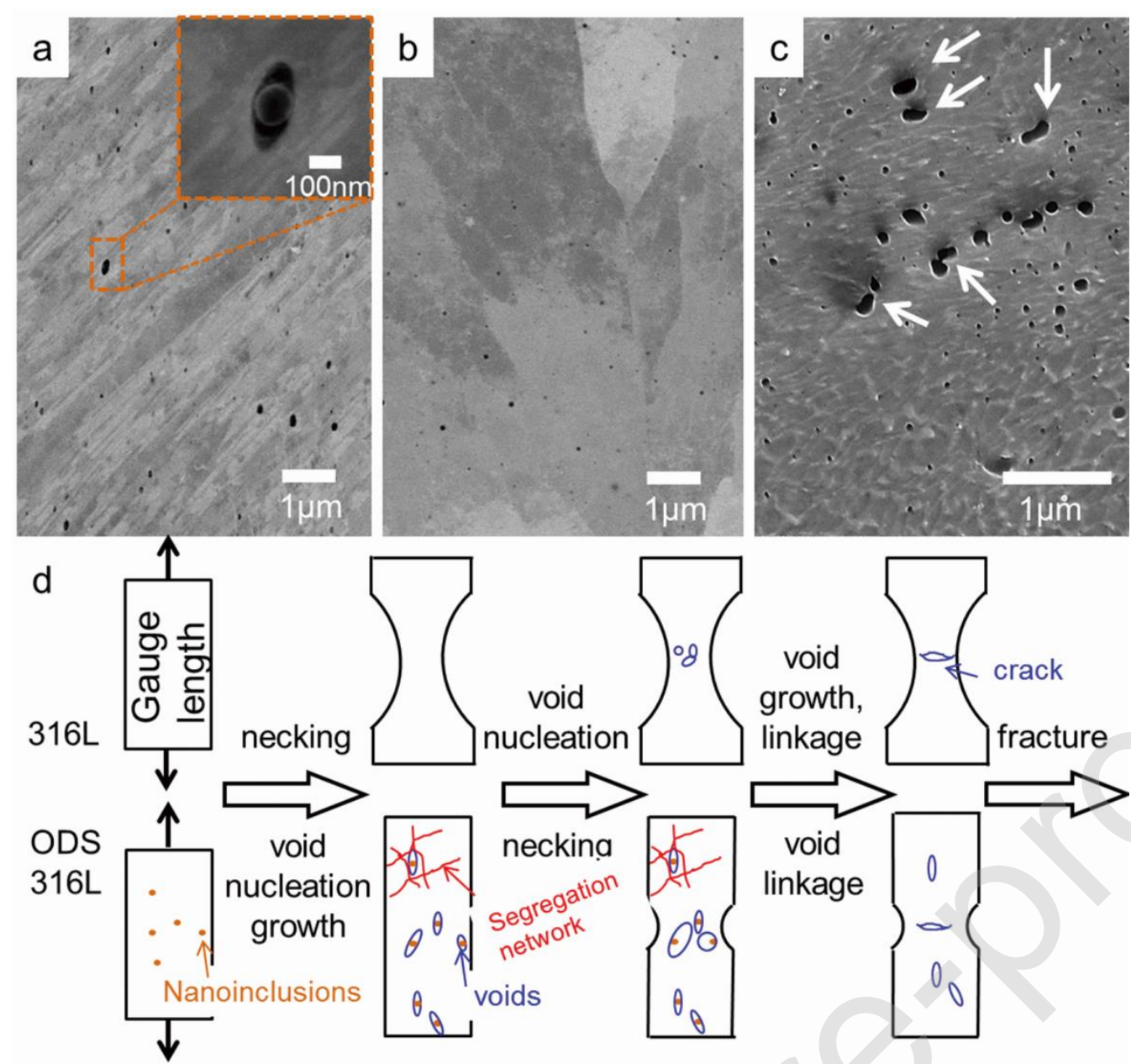

Fig. 8. Elongated nano-voids observed in the non-necking section of the sample tested at RT (a), Nanoinclusions located in the non-necking section without voids formed in the sample at $250^{\circ} \mathrm{C}$ (b), voids growth suppression by nanostructured segregation network (c), summarize of the necking mechanism of SLM ODS-316L and the traditional fabricated 316L as comparison (d). 
Table list:

Table 1 Process parameters of ODS 316L stainless steels with different amount of $\mathrm{Y}_{2} \mathrm{O}_{3}$ additions, $P=$ Laser power, $v=$ scanning speed, $d=$ hatch spacing, $h=$ layer thickness, $w=$ power density

\begin{tabular}{|l|l|l|l|l|l|l|l|l|}
\hline No. & $P$ & $v$ & $d$ & $h$ & $w^{*}$, & Nominal & Real $\mathrm{Y}_{2} \mathrm{O}_{3}$, & Density, \\
$(\mathrm{W})$ & $(\mathrm{mm} / \mathrm{s})$ & $(\mathrm{mm})$ & $(\mathrm{mm})$ & $\left(\mathrm{J} / \mathrm{mm}^{3}\right)$ & $\mathrm{Y}_{2} \mathrm{O}_{3}(\mathrm{wt} \%)$ & $(\mathrm{wt} \%)$ & $\left(\mathrm{g} / \mathrm{cm}^{3}\right)$ \\
\hline ODS-0 & 195 & 900 & 0.15 & 0.02 & 72.2 & 0 & 0 & 7.942 \\
\hline ODS-1 & 195 & 800 & 0.08 & 0.02 & 152 & 1 & 0.296 & 7.941 \\
\hline ODS-2 & 195 & 700 & 0.06 & 0.02 & 232 & 2 & 0.374 & 7.937 \\
\hline
\end{tabular}

* $w=P /(v d h)$ 